\title{
Surgical management of craniopharyngioma with third ventricle involvement
}

\author{
Danielle de Lara, M.D., ${ }^{1,2}$ Leo F. S. Ditzel Filho, M.D., ${ }^{1}$ Jun Muto, M.D., ${ }^{1}$ Bradley A. \\ Otto, M.D., ${ }^{2}$ Ricardo L. Carrau, M.D., ${ }^{2}$ and Daniel M. Prevedello, M.D. ${ }^{1}$ \\ Departments of ${ }^{1}$ Neurological Surgery and ${ }^{2}$ Otolaryngology-Head and Neck Surgery, The Ohio State University, \\ Columbus, Ohio
}

\begin{abstract}
Craniopharyngiomas are notorious for their ability to invade the hypothalamus and third ventricle. Although several transcranial approaches have been proposed for their treatment, the endonasal route provides direct access to the tumor with no need for cerebral retraction or manipulation of the optic apparatus. After the lesion is debulked, the unique angle of approach achieved with this technique enables the surgeon to perform an extra-capsular dissection and visualize the walls of the third ventricle, the foramina of Monro, and the anterior comissure. Moreover, the enhanced magnification and lighting afforded by the endoscope facilitate safe tumor removal, particularly in areas where there is loss of clear lesion delimitation and greater infiltration of the surrounding structures.

Herein we present the case of a 68-year-old female patient with a 3-month history of visual deterioration accompanied by worsening headaches. Investigation with magnetic resonance imaging revealed a heterogeneous mass in the suprasellar region, extending into the third ventricle and displacing the pituitary gland and stalk inferiorly. Hormonal profile was within expected range for her age. An endonasal, fully endoscopic, transplanum transtuberculum approach was performed. Gross-total removal was achieved and pathology confirmed the diagnosis of craniopharyngioma. Postoperative recovery was marked by transient diabetes insipidus. Closure was achieved with a pedicled nasoseptal flap; despite exploration of the third ventricle, there was no cerebrospinal fluid leakage. Pituitary function was preserved. Visual function has fully recovered and the patient has been uneventfully followed since surgery.

The video can be found here: http://youtu.be/it5mpofZ10Q.

(http://thejns.org/doi/abs/10.3171/2013.V1.FOCUS12330)
\end{abstract}

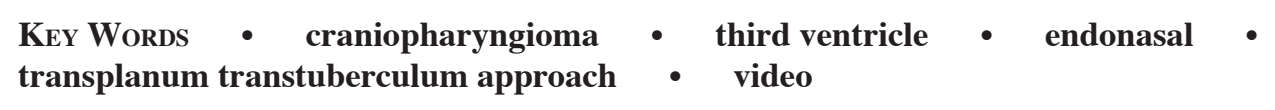

Manuscript submitted October 2, 2012.

Accepted October 23, 2012.

Please include this information when citing this paper: DOI: 10.3171/2013.V1.FOCUS12330.

Address correspondence to: Daniel M. Prevedello, M.D., The Ohio State University, Department of Neurosurgery, N-1011 Doan Hall, 410 W. 10th Avenue, Columbus, OH, 43210. email: Daniel. prevedello@osumc.edu.. 